Dr. Faisal Solaiman BDS, MPH

Senior Lecturer

Dept. of Prosthodontics

City Dental College, Dhaka

Dr. Shamim Ahmed

BDS, MPH

Chief Consultant

Tamanna Dental Zone, Dhaka

Dr. Syeda Mahmuda Akhter

BDS

Senior Lecturer

Dept. of Periodontology

Oral Pathology \& Oral Medicine

City Dental College, Dhaka

Dr. Arup Kumar Saha

BDS, MPH

Asst. Professor

Dept. of Dental Public Health

City Dental College, Dhaka

Dr. Helal Uddin BDS, MPH

Research Assistant \& MS (Resident)

Dept. of Orthodontics

Bangabondhu Sheikh Mujib

Medical University, Dhaka

Dr. Md. Abul Kalam Azad

BDS

MS (Resident)

Dept. of Conservative Dentistry

Bangabondhu Sheikh Mujib

Medical University, Dhaka

Dr. A. S. M. Rafiul Haque

BDS

Dental Surgeon

Dhaka

Correspondence to:

Dr. Faisal Solaiman BDS, MPH

Senior Lecturer

Dept. of Prosthodontics

City Dental College, Dhaka

E-mail: dr.faisal17@ymail.com

\title{
Preventive Practice on Hepatitis B Virus Infection among Dentists in Selected Hospitals at Dhaka City, Bangladesh
}

\author{
Abstract: \\ Aims: The study was carried out among 120 dentists working in the \\ selected hospitals of Dhaka city to find out the preventive practice \\ on hepatitis B virus (HBV) infection.
}

Methods: A descriptive type of cross-sectional study was carried out involving 120 dentists working in the selected hospitals of Dhaka city from December 2011 to March 2012 to quantify the preventive practice on HBV infection through a pretested semi-structured questionnaire. Results were analyzed by using the software SPSS 16.0 version (Chicago). Then analyzed data were presented according to the variables of the study showing percentage relationship between variables using appropriate statistical method.

Results: Mean age of the dentists was $26.43 \pm 6.29$ (range, 25-45) years where $74.17 \%$ were male and $25.83 \%$ were female. Among 120 respondents, $20.83 \%$ obtained BDS degree along with a postgraduate training (PGT) in any of the respective fields of dentistry. Others obtained MS in dentistry (21.67\%), MPH in dentistry $(10.83 \%), \mathrm{PhD}$ in dentistry $(9.17 \%)$, DDS in dental surgery $(10 \%)$ and FCPS in dentistry $(6.67 \%)$. Academic positions of the respondents were $33.33 \%$, assistant professors, $26.67 \%$ associate professors, $19.17 \%$ medical officers, and $17.5 \%$ were lecturers. Majority (93.3\%) dentists knew about HBV transmission, prevention, symptoms, risks, and concurrences. Out of them, $87.5 \%$ reported having been tested for HBV which was associated with their designations $(p=0.013)$ and more than $75 \%$ reported having been vaccinated against $\mathrm{HBV}$.

Conclusions: A high level of knowledge and attitude towards practice in the prevention of HBV was found to be very good among the dentists of Dhaka city though seemed it was not always possible to take precaution for handling emergency patients. Further broad scale studies would be needed to have decisive results.

Key words: Hepatitis B virus (HBV), preventive measures and practice, emergency management.

\section{Introduction:}

Hepatitis $B$ virus (HBV) is very common in Asia and moreover its appearance in Africa and Europe is remarkable. ${ }^{1}$ In fact, it is a major public health problem in most parts of the world. The prevalence of HBV varies from country to country depending upon a behavioral, environmental and host factors. ${ }^{1,3,7,8}$ Hepatitis B (formerly known as "serum hepatitis") is an acute systemic infection with major pathology in liver, caused by HBV and transmitted usually by the parenteral route. ${ }^{3}$ There is also evidence of a close association between HBV and primary liver cancer and at least one million chronically infected persons die each year of chronic liver disease, including cirrhosis and liver cancer. ${ }^{2,3,7}$ Three thousand six hundred and ten patients with acute hepatitis in two large hospitals in Dhaka city of Bangladesh were tested for hepatitis B surface antigen (HBsAg). Besides, 780 commercial blood donors, 126 doctors and 576 apparently healthy persons were also tested. 
Passive haemagglutination technique was applied for this test. Patients with post-transfusion hepatitis and doctors with acute hepatitis showed the highest incidence, being $60 \%$ and $65.5 \%$, respectively. HBsAg was detected only in $15.4 \%$ of children and $27.2 \%$ of adult patients with acute hepatitis. ${ }^{4}$ The ability of radioimmunoassay for hepatitis $B$ e antigen $(\mathrm{HBeAg})$ to predict infectivity in exposed medical personnel by analyzing 390 samples of sera positive for HBsAg that were implicated in accidental inoculations of known outcome. The radioimmunoassay detected $\mathrm{HBeAg}$ or its antibody (anti-HBe) in $91 \%$ of the donors' sera. The incidence of hepatitis B was 19\% (44 of 234) in recipients of $\mathrm{HBeAg}$-positive sera but was only $2.5 \%$ (3 of 121) in recipients of sera positive for anti-HBe, and nil (none of 35) in recipients of sera negative for $\mathrm{HBeAg}$ and anti-HBe. The known relation of $\mathrm{HBeAg}$ and infectivity was quantified by radioimmunoassay as a risk ratio of 10:1 (HBeAg-positive to HBeAgnegative) for this type of exposure. ${ }^{5}$ Workers engaged in direct patient care appear to be at greater risk of both contracting clinical hepatitis and acquiring serologic evidence of hepatitis B infection. Several studies suggested that exposure to blood products, rather than direct patient care per se, is the prime risk factor HBV infection where physicians and nurses in surgical specialties had higher rates of both symptomatic hepatitis and seropositivity than in those in medical specialties. ${ }^{3-6}$ Among physicians, a progression from low to higher seropositivity rate was noted considering physicians with little exposure to blood products, as psychiatrists, (seropositivity rate $3.2 \%)$, those with moderate exposure, as internists $(7.7 \%)$ and those with maximal exposure, as general surgeons $(18.4 \%)^{6}$

This was the first attempt to observe the knowledge and attitude of the dentists of Dhaka city of Bangladesh towards the preventive practice against the HBV infection.

\section{Materials and Methods:}

A descriptive type of cross-sectional study was carried out among 120 dentists who were working in the Bangladesh Institute of Research and Rehabilitation for Diabetes, Endocrine and Metabolic Disorders (BIRDEM), City Dental College Hospital and Pioneer Dental College Hospital of Dhaka city. The dentists were randomly selected and clinical data were recorded from the dentists during the period of December 2011 to March 2012.

\section{Inclusion criteria-}

a) Dentists had clinical experience $>3$ years.

b) Male and female.

c) Who were willing to give consent or participate to fill up the questionnaire.

Exclusion criteria- Dentists who refused to provide informed consent.

\section{Statistical Analysis:}

The collected data were edited by checking, rechecking, analyzed by using the software SPSS 17.0 version (Chicago).

\section{Results:}

Mean age of the dentists was $26.43 \pm 6.29$ (range, 2545) years where $74.17 \%$ were male and $25.83 \%$ were female. Among 120 respondents, $20.83 \%$ obtained bachelor of dental surgery (BDS) degree along with a postgraduate training (PGT) in any of the respective fields of dentistry. Others obtained master of science (MS) in dentistry $(21.67 \%)$, master of public health (MPH) in dentistry $(10.83 \%)$, doctorate (PhD) in dentistry $(9.17 \%)$, postgraduate diploma (DDS) in dental surgery (10\%) and fellow (FCPS) of the college of physicians and surgeons (6.67\%). Designations of the respondents were $33.33 \%$, assistant professors, $26.67 \%$ associate professors, $19.17 \%$ medical officers, and $17.5 \%$ were lecturers. Majority (93.3\%) dentists knew about HBV transmission, prevention, symptoms, risks, and occurrences. Out of them, $87.5 \%$ reported having been tested for HBV which was associated with their affiliations $(p=0.013)$ and more than $75 \%$ reported having been vaccinated against HBV.

The Knowledge on possibility to carry HBV by healthy person was $93.3 \%$. They expressed that healthy person may carry HBV and $6.7 \%$ told that it would not be possible to carry HBV by healthy person and $37.5 \%$ respondents indicated that chronic persistent hepatitis and $80 \%$ respondents answered that liver cirrhosis are the consequences of HBV infection. Among them, $77.5 \%$ opined that hepatocellular carcinoma is the consequences of HBV infection, $48.3 \%$ respondents indicated commercial sex worker as high risk group, $81.7 \%$, Intravenous drug user (IVDU)s, $75 \%$, blood recipient and $73.3 \%$ were clinical care provider. The knowledge regarding vaccination were $8.0 \%$ told about two doses of vaccine, $11.7 \%$ told three doses of vaccine $87.5 \%$ told four doses of vaccine. The subject were $87.5 \%$ tested their blood for HBsAg and $12.5 \%$ had never tested their blood for HBsAg. The knowledge of prevention HBV infection of the respondents were $40 \%$ opined that avoid free sex is the preventive measure against HBV followed by $87.5 \%$ by screening for HBsAg, $100 \%$ by avoid using common syringe, $90 \%$ by vaccination and $100 \%$ told aseptic measures can prevent HBV infection. In statistical analysis cosidering as dependent variable, it has been found that there were a statistical significant $(p=0.013)$ association between socio-demographic factor (designation of the respondents) preventive practice vaccine taken or not) against HBV infection. 
Table-1: Socio-demographic distribution of the Respondents. $(n=120)$

\begin{tabular}{|c|c|c|c|c|c|}
\hline \multirow{3}{*}{ Gender } & \multicolumn{2}{|c|}{ Frequency } & \multirow{2}{*}{\multicolumn{3}{|c|}{$\begin{array}{c}\text { Percentage } \\
74.17\end{array}$}} \\
\hline & \multirow{2}{*}{\begin{tabular}{|c|} 
Male \\
Female \\
\end{tabular}} & \multirow[t]{2}{*}{89} & & & \\
\hline & & & \multicolumn{3}{|c|}{25.83} \\
\hline \multirow{6}{*}{ Age } & Years & Frequency & Percentage & Mean & SD \\
\hline & $25-29$ & 44 & 36.7 & \multirow{5}{*}{26.43} & \multirow{5}{*}{ \pm 6.29} \\
\hline & $30-34$ & 42 & 35.0 & & \\
\hline & $35-39$ & 17 & 14.2 & & \\
\hline & $40-44$ & 15 & 12.5 & & \\
\hline & $>45$ & 2 & 1.7 & & \\
\hline \multirow{6}{*}{$\begin{array}{l}\text { Designation } \\
\text { of } \\
\text { Respondents }\end{array}$} & & & Frequency & \multicolumn{2}{|c|}{ Percentage } \\
\hline & \multicolumn{2}{|l|}{ Lecturer } & 21 & \multicolumn{2}{|c|}{17.5} \\
\hline & \multicolumn{2}{|c|}{ Medical Officer } & 23 & \multicolumn{2}{|c|}{19.17} \\
\hline & \multicolumn{2}{|c|}{ Assistant Professor } & 40 & \multicolumn{2}{|c|}{33.33} \\
\hline & \multicolumn{2}{|c|}{ Associate Professor } & 32 & \multicolumn{2}{|c|}{26.67} \\
\hline & \multicolumn{2}{|c|}{ Professor } & 4 & \multicolumn{2}{|c|}{3.33} \\
\hline
\end{tabular}

Table-2: Distribution of Respondents' knowledge on way of transmitting HBV infection (multiple responses).

$[\mathrm{n}=120]$

\begin{tabular}{||l|c|c||}
\hline \multicolumn{1}{|c|}{ Way of transmission } & Frequency & Percentage \\
\hline Contaminated syringe /needle & 112 & 93.3 \\
\hline Cutting instruments in saloon & 57 & 47.5 \\
\hline Through saliva /other secretions & 65 & 54.2 \\
\hline Sexual intercourse & 101 & 84.2 \\
\hline Through placenta & 61 & 50.8 \\
\hline Blood transfusion & 103 & 85.8 \\
\hline Through tattooing & 53 & 44.2 \\
\hline Intravenous drug user (IVDU) & 107 & 89.2 \\
\hline \hline
\end{tabular}

Table-3: Distribution of Respondents' knowledge of high risk group of HBV infection (multiple responses). [ $n=120]$

\begin{tabular}{|l|c|c|}
\hline \multicolumn{1}{|c|}{ High risk group } & Frequency & Percentage \\
\hline Sex worker & 58 & 48.3 \\
\hline Injected drug user & 98 & 81.7 \\
\hline Blood receiver & 90 & 75 \\
\hline Care giver & 88 & 73.3 \\
\hline
\end{tabular}

Table-4: Distribution of Respondents by knowledge of prevention of HBV infection (multiple responses).

[n=120]

\begin{tabular}{|l|c|c|}
\hline \hline \multicolumn{1}{|c|}{ Preventive measures taken } & Frequency & Percentage \\
\hline Avoid free sex & 48 & 40 \\
\hline Screening for HbsAg & 105 & 87.5 \\
\hline Avoid common syringe & 120 & 100 \\
\hline Vaccination & 108 & 90 \\
\hline Aseptic precaution & 120 & 100 \\
\hline
\end{tabular}

City Dent. Coll. J Volume-10, Number-1, January-2013
Table-5: Association between socio-demographic factor (designation of the Respondents) preventive practice (Vaccine taken or not) against HBV infection.

[n=120]

\begin{tabular}{|c|c|c|c|c|c|c|c||}
\hline \hline \multirow{5}{*}{$\begin{array}{c}\text { Vaccine } \\
\text { taken }\end{array}$} & \multicolumn{5}{|c|}{ Designation of the Respondents } & \multirow{2}{*}{ T-value } \\
\cline { 2 - 7 } & Lecturer & $\begin{array}{c}\text { Medical } \\
\text { Officer }\end{array}$ & $\begin{array}{c}\text { Assistant } \\
\text { Professor }\end{array}$ & $\begin{array}{c}\text { Associate } \\
\text { Professor }\end{array}$ & Professor & & (ç) \\
\hline Yes & 18 & 21 & 39 & 27 & 3 & 108 & \\
\hline No & 3 & 2 & 1 & 5 & 1 & 12 & \multirow{2}{*}{0.013} \\
\hline Total & 21 & 23 & 40 & 32 & 4 & 120 & \\
\hline
\end{tabular}

Figure-1: Distribution of respondents by last degree obtained.

[n=120]

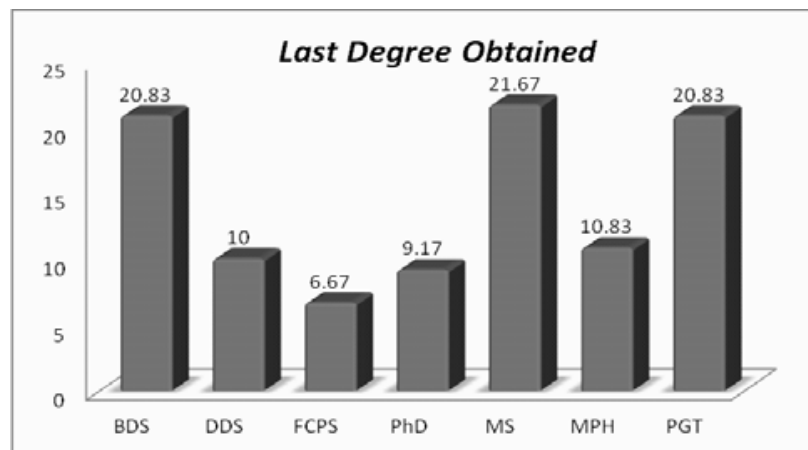

Figure-2: Distribution of respondents by their knowledge on symptoms of HBV infection.

$[\mathrm{n}=120]$

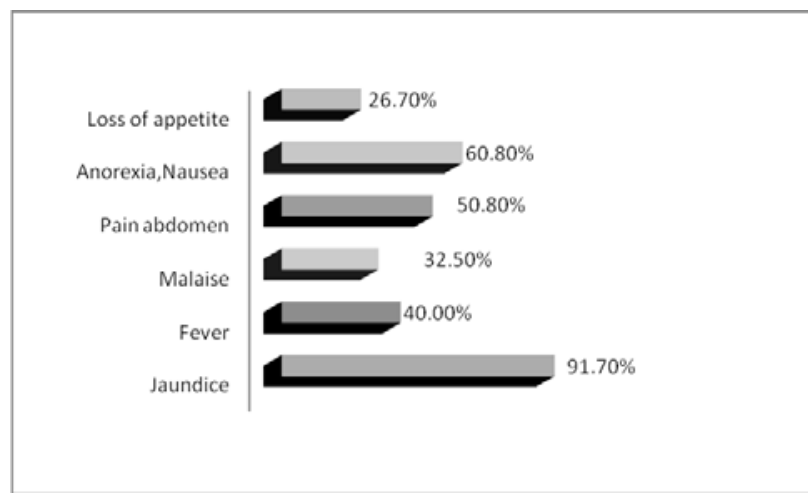

\section{Discussion:}

Chronic HBV infection causes liver cancer. ${ }^{1,3,7}$ In order to advance HBV and liver cancer awareness and prevention, it is important to identify existing gaps in knowledge and preventive practices among Asian Americans. Therefore, the authors administered a written questionnaire to 199 adults in the AsianAmerican community of the San Francisco Bay Area, California. Although the majority of adults had at least a college education, knowledge regarding HBV transmission, prevention, symptoms, risks, and occurrences were low. Fewer than $60 \%$ reported having been tested for $\mathrm{HBV}$, only $31 \%$ reported having been vaccinated against HBV, and only $44 \%$ reported having had their children vaccinated. ${ }^{7}$ 
Present study showed that $20.83 \%$ obtained BDS and PGT, respectively, $21.67 \%$ obtained MS, $10.83 \% \mathrm{MPH}$, $9.17 \% \mathrm{PhD}, 10 \%$ DDS and $6.67 \%$ FCPS degrees. Out of 120 respondents, majority $(93.3 \%)$ dentists knew about HBV transmission, prevention, symptoms, risks, and occurrence. Among them, 87.5\% reported having been tested for HBV and more than $75 \%$ reported having been vaccinated against HBV. Those with higher designation levels were significantly more likely to have been tested for HBV and to have had their vaccines against HBV infection. This study showed knowledge regarding HBV among dentists was good and preventive practice was associated with increased level of designation of the dentist. This is similar with previously mentioned study. ${ }^{2-4}$

Present study showed that among 120 dentists, knowledge regarding HBV was good. Here vaccination rate was $87.5 \%$, which was associated with the designations of the dentists $(p=0.013)$. Dentists had the poorest awareness compliance due to inadequate aseptic measure for handling every patient which was similar to the study of Sofola OO, et al. ${ }^{8}$ where knowledge of the HBV infection was inadequate among 159 persons. There was an overall vaccination rate of $40.3 \%$. However, dentists were significantly more likely to be vaccinated $(p=0.014)$. Students had the poorest compliance. $54 \%$ of respondents gave reasons suggestive of complacency for non-uptake. ${ }^{8}$

One thousand nine hundred twenty one questionnaires were collected; 312 were from $\mathrm{H} / \mathrm{S}-\mathrm{CWs}$ and 1609 from UPP. The answer rate was $100 \%$ for $\mathrm{H} / \mathrm{S}$-CWs and $92.7 \%$ among the UPP population. Knowledge about HBV and HCV was better for H-CWs compared to SCWs. For HBV, route of transmission was the best known field (85.2\% of right answers) and use of blood sample screening was the least known field (54.2\%). Vaccination was advanced by $50.6 \%$ of $\mathrm{H} / \mathrm{S}-\mathrm{CWs} .9$ Present study showed that knowledge about HBV was good. Knowledge about causative agent, route of transmission by contaminated syringe /needle, avoid using common syringe /needle, taking vaccine against HBV ideal age of vaccination was the best field $(100 \%$ of right answers) healthy carrier is burden to the society was the least known field $(30 \%)$. This finding was similar with previous findings. ${ }^{9}$

Another study was conducted to observe the knowledge, attitude and practices among health care workers on needle-stick injuries in Saudi Arabia. Of the 70 health care workers, $47(67 \%)$ were females, $65(93 \%)$ were aged between 30 to 50 years (mean $38.7 \pm 6.6$ years), and $46(66 \%)$ were nurses in the wards. Forty-eight $(69 \%)$ of the subjects had been working as health care workers for $10-20$ years, $54 \%$ have been working in Saudi Arabia for 5-10 years. All the subjects were negative for HBsAg, anti-HCV and anti-HIV. Also, 59 subjects ( $84 \%$ ) had been vaccinated against HBV, while 11 (16\%) had neither been vaccinated or investigated for immunity to past exposure. Of the 59 subjects, only $6(10 \%)$ had been tested for anti-HBs antibodies after HBV vaccination to check their response. ${ }^{10}$ Present study showed that most of the dentists were found $36.7 \%$ age ranged from $25-29$ years. The reminders $35 \%$ of respondents were aged $30-34$ years, $14.2 \%$ were aged $35-39$ years, $12.5 \%$ were aged $40-44$ years and $1.7 \%$ of the respondent age ranged more than 45 years with the mean age $26.43 \pm 6.29$. Out of 120 respondents $74.17 \%$ were male and $25.83 \%$ were female. Among them, $87.5 \%$ respondents screened for $\mathrm{HBsAg}$ and 105 subjects $(87.5 \%)$ had been vaccinated against HBV infection, while $15(12.5 \%)$ had never vaccinated. This is almost similar with previous study. ${ }^{10}$

One hundred twenty two vaccinators were interviewed. About $80 \%$ were male and $20 \%$ were female. Forty three percent had intermediate, $27 \%$ matriculate, $23 \%$ graduate and $4.9 \%$ postgraduate education. Majority $(95 \%)$ mentioned that liver is affected by HBV. Only $64 \%$ responded that a virus is the cause. Regarding transmission of HBV, $47 \%$ mentioned infected blood transfusion, $50 \%$ contaminated needles, $25 \%$ unsterilized instruments and only $22 \%$ mentioned sexual contact. It is diagnosed clinically and by laboratory according to $22 \%$ and $76 \%$ respondents, respectively. Among them, $65 \%$ mentioned that it would be curable and $38.5 \%$ said it would be preventable. Vaccination, use of disposable syringes, use of sterilized instruments and practicing safe sex can prevent HBV infection according to $34 \%, 30 \%, 13 \%$ and $6.5 \%$ vaccinators, respectively. ${ }^{11}$ Present study showed that among 120 dentists, majority (80\%) mentioned that liver cirrhosis would occur from HBV infection. Hundred (100)\% opined that HBV was the cause. Regarding transmission of HBV, most of the respondents gave multiple answers. Ninety three (93.3)\% answered in favor of contaminated syringe /needle followed by $47.5 \%$ was through cutting instruments in saloon, $54.2 \%$, through saliva or secretion of infected person, $84.2 \%$ through sexual intercourse, $50.8 \%$, through placenta, $85.8 \%$, through blood transfusion, $44.2 \%$, through tattooing and $89.2 \%$, through common needle sharing among IVDU. Taking aseptic precautions, avoid common syringe /needle, vaccination, HBsAg screening and avoid free sex can prevent HBV infection according to $100 \%, 100 \%, 90 \%$, $87.5 \%$ and $40 \%$ nurses, respectively. This was also similar type of findings of the previous studies. ${ }^{10,11}$ 


\section{Conclusions:}

The present study showed high level of preventive practice against HBV infection by taking sufficient aseptic measures and they also added it was not always possible to take precaution for handling emergency patients. Although the knowledge and attitude towards practice of prevention of HBV was found to be very good among the dentists. Attitude towards practice for prevention of diseases need to be improved. Vaccination against HBV coverage was suboptimal among the Dhaka health care service providers. It was observed that television and newspapers would be very important media from where people can learn a lot about HBV infection. Basic barrier techniques to prevent cross-infection were not being used consistently. Nationwide guidelines for barriers techniques and hepatitis vaccinations should be developed and disseminated to health care workers.

\section{References:}

1. Kumar PJ, Clerk ML. Liver, biliary tract and pancreatic disease. In: Kumar Parveen, Clerk Michel, Clinical Medicine: A text book for medical students and doctors. 3rd ed. India: Butles and tanner Ltd, Frame and London;1995:253-55.

2. Park K. Viral Hepatitis. In: Park's text book of preventive and social medicine. 15th ed. India: M/S Bannasidas Bhanot;1997:157-59.

3. World Health Organization. Regional office for South East Asia, New Delhi, India. Prevention of Hepatitis B in India [Online] 2002 Aug [cited 2011 Sept 01].

4. Islam MN, Islam KM, Islam N. Hepatitis B virus infection in Dhaka, Bangladesh. Bangladesh Med Res Counc Bull 1984;10(1):1-6.

5. Werner BG, Grady GF. Accidental hepatitis B surface antigen positive inoculations: use of e antigen to estimate infectivity. Ann Intern Med 1982;97:367-69.

6. Herbert E. Segal, Craig H. Llewellyn, Gilbert Irwin, William H. Hepatitis B antigen and antibody in the U.S. Army: Prevalence in health care personnel. Am J Pub Health 1976;66(7):667-71.

7. Charlotte AW, Steven YL, Samuel KS, et al. Hepatitis B and liver cancer Knowledge and preventive practices among Asian Americans in the San Francisco bay area, California. Asia Pacific J Cancer Prev 2007;8:127-34.

8. Sofola OO, Uti OG. Hepatitis B virus infection and prevention in the dental clinic: knowledge and factors determining vaccine uptake in a Nigerian dental teaching hospital. Nig Q J Hosp Med 2008;18(3):145-48.

9. Sahajian F, Voirin N, Vanhems $P$, et al. Knowledge of hepatitis B among underprivileged people. Rev Epidemiol Sante Publique 2005;53(1):25-42.
10. Alam M. Knowledge, attitude and practices among health care workers on needle-stick injuries. Annals of Saudi Med 2002;22:5-6.

11. Shah S, Nisar N, Qadri MH. Knowledge regarding hepatitis-B among EPI. Pak J Med Sci 2007; 23(4):53841. 